with malevolent cases.

Your editorial fails to inform readers that the ORI is not merely proposing to measure "other" misbehaviour, but also "perceived" misbehaviour, which is key to our objection. The survey will not generate a measure of misconduct, but a recording of hearsay or innuendo. For example, one question asks whether the respondent knows of colleagues "citing an article they had not read firsthand". This orwellian approach, which encourages scientists to spy on each other's reading habits, will not lead to clarification of the ethical status of biomedical research.

You imply that there was a conspiracy behind the creation of the current definition of research misconduct. This is incorrect. The record clearly shows that there was an extended debate and many opportunities for public comment. We have supported efforts to improve education in research ethics, as I stated publicly in remarks at the 10 October Institute of Medicine town meeting. FASEB's August 2000 letter commenting on the draft PHS Policy for Instruction in the Responsible Conduct of Research states: "Students and trainees must have instruction in the responsible conduct of research. But the extension of this requirement to 'all staff' including subcontractors and consultants will result in an enormous involvement of time and resources." Our policy statements show our consistent commitment to the responsible conduct of research. There is no basis for implying that our position condones, supports or protects unethical behaviour. Steven L. Teitelbaum

President, FASEB, Dept of Pathology and Immunology, Washington University School of Medicine, MS 90-31-649, 216 Kingshighway, St Louis, Missouri 63110, USA

\section{Sounding the alarm on underwater noise}

\section{Sir - Your News feature on fisheries} management (Nature 419, 662; 2002) raises the important point of considering each fishery in the context of its larger ecological context, although you identify overfishing as the root cause of fisheries depletion. This perspective puts the onus of fisheries health exclusively on the fishing industry.

Agricultural runoff, the pollution and disappearance of estuarine and wetland nurseries and, increasingly, anthropogenic 'noise' are all compromising ocean health

— to such a degree that fisheries population crashes might occur even without commercial overharvesting.

Only recently has anthropogenic noise been acknowledged as a threat to marine ecology, as evidenced by whale and dolphin strandings caused by military sonar (Nature 415, 106; 2002). Noises caused by shipping, underwater seismic exploration, sonar, underwater telemetry and military exercises have all increased dramatically over the past decade. Many fish rely on acoustical perception to hunt, school, evade predators and find mates. Cluttering their acoustical niches with noise affects their survival prospects. Michael Stocker

Seaflow.org, PO Box 559, Lagunitas,

California 94938, USA

\section{Why astronomy is the star of the news show}

Sir - Space science news is good news, according to the Pew Research Center for the People and the Press, which tracks the "most closely followed" news stories in the United States (http://people-press.org/ reports). From 1986 to 1999, the Pew study found 689 such items, 39 of them related to science, medicine and the weather. To a striking degree, these 39 stories had disturbing news to tell — earthquakes or other natural calamities, nuclear power, AIDS or controversies over cloning. Virtually every 'good news' science story was about space science, for example reports of the Hubble Space Telescope (1990) and Mars Pathfinder (1997) missions. The only other scientific subject reported in a positive light was Viagra.

Perhaps this 'good news' feature of astronomy and space science helps to explain their broad popularity. A recent NSF survey reports that $74 \%$ of adults in 1999 were interested in space exploration, and many people (57\% in 1999) agreed that it is worth its costs (see "Public Attitudes Towards Space Science", by H.A.S., in Space Science Reviews Vol. 102, 3-4, Kluwer, 2002.)

Politicians mindful of public morale might want to note this phenomenon, as might budget-conscious managers who seem to suspect that astronomy and space science do not give adequate value-fordollar (and/or are badly managed). The current US administration, for example, and its Office of Management and Budget (OMB), in an effort to remedy these perceived faults, are "measuring the performance" of government-supported research so that "spending on fundamental research will be judged by formal 'performance criteria'" (see Nature 415, 466-467; 2002). In the spirit of "improving management", the OMB first proposed to move the National Science Foundation's astronomy funding to other agencies with little clear reason, support or success
— and subsequently proposed the opposite: moving some astronomy (and other research) funding into the foundation (see Nature 414, 680; 2002).

How does one calculate value-fordollar in a discipline such as astronomy, whose primary product is knowledge? As succinctly (but unhelpfully) put by one astronomer, Nicholas Copernicus, the aim of a scientist is "to seek the truth in all things". But without a sense of the worth of research accomplishments, how can those formal performance criteria for measuring and managing be identified, and then seriously and sensibly applied? Surely one lesson of the collapse of the telecommunications giant Enron is that 'measuring' and 'managing' are techniques that are themselves subject to error, incompetence, inefficiency and worse.

This is where the good-news aspect of astronomy comes in. Gerald Holton and Gerhart Sonnert (Issues in Science and Technology, 61-65; Fall 1999) have proposed a model in which basic research falls into three categories whose respective goals are knowledge, applied knowledge and (after Thomas Jefferson) knowledge with the realization that something practical might ensue. John F. Kennedy expressed a fourth goal: the public spirit. As he put it when justifying the Apollo programme: "We choose to go to the Moon in this decade, and do the other things, not because they are easy, but because they are hard... No single space project in this period will be more impressive to mankind." In the words of the current NASA Administrator, Sean O'Keefe, NASA's “mandate is to pioneer the future... NASA's work inspires Americans and unites people."

Public spirit and public interest, though intangible, are reflected in the media. New planets, new insights into the creation of the Universe, and other cosmic discoveries regularly merit upbeat front-page coverage because the pictures are inspirational, the stories are relatively easy to understand, the adventures are exciting, the discoveries are often meaningful, and the successes make us happy to be alive. Other science research disciplines (and their public outreach programmes) might also benefit from performance criteria that include a mediabased appraisal of public attitudes. At least for astronomy the news is good accountants, please add 10 points. Howard A. Smith

Harvard-Smithsonian Center for Astrophysics, 60 Garden Street, Cambridge,

Massachusetts 02138, USA

\section{correspondence}

contributions to correspondence may be submitted to corres@nature.com. They should be no longer than 500 words, and ideally shorter. 